\title{
The Impact of Psychological Distress on Incident Functional Disability in Elderly Japanese: The Ohsaki Cohort 2006 Study
}

\author{
Yasutake Tomata*(D), Takashi Watanabe, Fumiya Tanji ${ }^{\circledR}$, Shu Zhang ${ }^{\circledR}$, Yumi Sugawara \\ and Ichiro Tsuji \\ Division of Epidemiology, Department of Health Informatics and Public Health, Tohoku University School of \\ Public Health, Graduate School of Medicine 2-1, Seiryo-machi, Aoba-ku, Sendai 980-8575, Japan; \\ tkswatanabe@med.tohoku.ac.jp (T.W.); ftanji-thk@umin.ac.jp (F.T.); zhangshu@med.tohoku.ac.jp (S.Z.); \\ yumi1717@med.tohoku.ac.jp (Y.S.); tsuji1@med.tohoku.ac.jp (I.T.) \\ * Correspondence: y-tomata@med.tohoku.ac.jp; Tel.: +81-22-717-8123
}

Received: 7 October 2018; Accepted: 7 November 2018; Published: 8 November 2018

\begin{abstract}
Background: Although psychological distress is known to be a risk factor for death, there are relatively few data on the impact of psychological distress on incident functional disability in older adults. The aim of this study was to examine the impact of psychological distress on incident functional disability in older adults. Methods: We conducted a cohort study of 12,365 disability-free individuals aged $\geq 65$ years who live in Ohsaki City, Japan. In 2006, the level of psychological distress was assessed using the K6 (range: 0-24 points). Data on 10-year functional disability were retrieved from the public Long-term Care Insurance database. The multivariate-adjusted hazard ratios (HRs) and population attributable fractions (PAFs) according to the K6 groups ( $<5,5-9,10-12$, and $\geq 13$ points) were estimated. Results: Among 94,636 person-years, incident functional disability occurred in 4533 persons (36.7\%). Significantly higher risk was observed in higher K6 score groups. The multiple-adjusted HRs (95\% CIs) of incident functional disability were 1.14 (1.06-1.22) for 5-9 points, 1.28 (1.15-1.43) for 10-12 points, and 1.62 (1.44-1.84) for $\geq 13$ points, in comparison with $<5$ points ( $p$-trend $<0.001$ ). The PAFs in each of the K6 score groups were $3.0 \%$ for $5-9$ points, $1.7 \%$ for $10-12$ points, and $2.6 \%$ for $\geq 13$ points. Conclusions: Even when mild to moderate, psychological distress had a considerable impact on incident functional disability in this cohort.
\end{abstract}

Keywords: psychological distress; K6; disability; elderly; population attributable fraction

\section{Introduction}

Prevention of functional disability among the older people is a significant healthcare issue [1]. The risk factors for functional disability have been studied in terms of not only physical status but also psychological factors [2,3]. Depression is well known as to be a risk factor for functional outcome [2-5], but major depression is relatively rare among the older population (e.g., weighted average prevalence $1.8 \%$ in USA, $0.4 \%$ in Japan [6]).

Psychological distress would be a more practical concept in the context of comprehensive mental disorder when considering public health strategies [7]. Psychological distress is suggested as a risk factor for mortality $[8,9]$. Although relatively few data are available, several studies have reported that psychological distress is risk factor for incident disability [10-12]. A cross-sectional study investigating the impact (population-attributable risk) of psychological distress concluded that it is the most important factor that limits activity in older adults [12]. Psychological distress is indeed prevalent among older adults (prevalence of $\mathrm{K} 6$ score $\geq 5$ points among Japanese adults aged $\geq 65$ years 
is $22.7 \%$ [ $\mathrm{K} 6$ score of $5-12: 20.48 \%, \mathrm{~K} 6 \geq 13: 2.25 \%$ ]) [13], and therefore may impact considerably on incident functional disability in that age group.

To verify this hypothesis, a prospective study to investigate the impact would be needed, because a cross-sectional study would generally be limited by reverse causality. To our knowledge, however, no prospective study has investigated this issue especially with regard to the impact of several levels of psychological distress.

The aim of the present study was to examine the impact of psychological distress on incident functional disability in older adults, focusing particularly on population attributable fractions (PAFs) calculated for several levels of psychological distress.

\section{Materials and Methods}

\subsection{Study Cohort}

The design of the Ohsaki Cohort 2006 Study has been reported in our design paper [14]. In brief, the source population for the baseline survey comprised all older citizens resident $(31,694$ men and women aged $\geq 65$ years) in Ohsaki City, Miyagi Prefecture, northeastern Japan, on December 2006. The survey included questions about psychological distress assessed by the Kessler six-item psychological distress scale (K6), as well as items on history of disease, motor function score, smoking, alcohol drinking, body weight, height, and social support.

The baseline survey was conducted between 1 and 15 December 2006, and the follow-up survey between 16 December 2006 and 30 November 2016. A questionnaire was distributed by the heads of individual administrative districts, and then collected by mail. In this survey, 23,091 persons who provided valid responses formed the study cohort. We excluded 6333 persons who did not provide written consent for review of their Long-term Care Insurance (LTCI) information, 1979 persons who had already been certified as having a disability by the LTCI at the time of the baseline survey, five persons who had died or moved away during the period of the baseline survey, and 2409 persons who left blank responses on the K6. Thus, 12,365 persons were analyzed for the purpose of this study.

During the 10-year study follow-up period, only 173 persons were lost to follow-up because of emigration from the study area; the follow-up rate was $98.6 \%$. From the resulting 94,636 person-years, the number of persons who developed incident functional disability was 4533 (36.7\%).

\subsection{Psychological Distress}

The exposure was psychological distress, as assessed by the K6 [15]. The Japanese version of the K6 has been validated in a previous study [16]. The K6 consists of six questions about how often an individual has felt the following in the last month: (1) nervous; (2) hopeless; (3) restless or fidgety; (4) so sad that nothing could cheer you up; (5) everything was an effort; and (6) worthless. The total K6 score ranged from 0 to 24 . In previous studies, three cut-off points of 5, 10 and 13 have been commonly used to screen for psychological stress [10,17-22]. Thus, we classified participants into four groups according to their $\mathrm{K} 6$ score $(<5,5-9,10-12$, and $\geq 13$ points).

\subsection{Covariates}

History of disease was collected by the question which asked whether participants have history about each disease (stroke, hypertension, myocardial infarction, diabetes, arthritis, and cancer).

Motor function was assessed by the Kihon Checklist including five binary questions (total point scores ranging from 0 to 5 ). We classified individuals with scores of $<3$ as having better motor function according to the validation study [23].

Smoking and alcohol drinking were assessed using questions that required a response of never, former, or current.

Self-reported weight and height were used to calculate BMI as weight $(\mathrm{kg})$ divided by the square of height $(\mathrm{m})$. 
The degree of social support was assessed by asking the following five binary questions [24]: (1) Do you have someone with whom you can talk when you are in trouble? (2) Do you have someone whom you can consult when you do not feel well? (3) Do you have someone who can help you with your daily housework? (4) Do you have someone who can take you to a hospital when you feel ill? and (5) Do you have someone who can take care of you if you become bedridden? This questionnaire was available only in Japanese. A validation study has reported that persons who responded "yes" had a higher mean score on the Lubben Social Network Scale [25]. In the previous study, if subjects considered themselves to have all five forms of support, they were defined as having "no lack" of social support, as detailed in previous studies [26-28].

\subsection{Follow-Up (Incident Functional Disability)}

Incident functional disability was defined by disability certification of the LTCI system. The LTCI is a mandatory social insurance to assist daily activities of the disabled elderly [29-31]. Every person aged $\geq 65$ years is eligible for formal caregiving services. To receive caregiving services through the LTCI system, a person must be certified according to the nationally uniform standard. The procedure for disability certification comprises two parts: (1) assessment of the degree of functional disability using a questionnaire developed by the Ministry of Health, Labor, and Welfare; and (2) reference to the Doctor's Opinion Paper prepared by the attending physician. If a person is judged to be eligible, the Municipal Certification Committee decides on one of seven levels, ranging from Support Level 1, Support Level 2, and Care Level 1 to Care Level 5. A previous study has shown that the level of LTCI certification is well correlated with ability of ADLs and with the Mini-Mental State Examination score [32]. LTCI certification has already been used as an outcome measure of incident functional disability in elderly individuals [26-28,33,34]. We also included mortality as an end point, certified by the local registry.

We obtained a dataset that included information on LTCI certification, death, or emigration from Ohsaki City based on an agreement with Ohsaki City Government related to Epidemiologic Research and Privacy Protection.

\subsection{Ethical Issues}

We considered the return of completed questionnaires to imply consent to participate in the study involving the baseline survey data and subsequent follow-up of death and emigration. We also confirmed information regarding LTCI certification status after obtaining written consent along with the questionnaires returned from the subjects at the time of the baseline survey. The Ethics Committee of Tohoku University Graduate School of Medicine (Sendai, Japan) reviewed and approved the study protocol.

\subsection{Statistical Analysis}

We counted the person-years of follow-up for each subject from 16 December 2006 until the date of incident functional disability, date of emigration from Ohsaki City, date of death, or the end of the study period (30 November 2016), whichever occurred first.

We used the Cox proportional hazard model to calculate the hazard ratios (HRs) and $95 \%$ confidence intervals (CIs) for incident functional disability according to the K6 score groups. Dummy variables were created for the $\mathrm{K} 6$ score groups, and the group with the lowest K6 score was used as a reference category. Multivariate models were adjusted for the following variables. Model 1 was adjusted for sex and age (65-69, 70-74, 75-79, 80-84, or $\geq 85$ years). Furthermore, Model 2 was adjusted for history of disease (stroke, hypertension, myocardial infarction, diabetes, arthritis, and cancer) (yes, no), motor function score ( $<3, \geq 3$, or missing), smoking (never, former, current, or missing), alcohol drinking (never, former, current, or missing), body mass index (in $\mathrm{kg} / \mathrm{m}^{2} ;<18.5$, 18.5-24.9, $\geq 25.0$ or missing), and social support (lacking, no lack, or missing). 
To consider the influence of excluding 2409 persons who left blank responses on the K6, we also checked the multiple-adjusted HRs (95\% CIs) using analysis by the multiple imputation method $(n=14,774)$ employing IBM SPSS Statistics ver. 24 (IBM Software Group, Chicago, IL, USA). We generated 10 different missing datasets.

We also calculated the PAFs for incident functional disability in the various K6 score groups. Two PAFs were estimated for the K6 score groups: (1) PAFALL assuming that the K6 score for all subjects would have changed to the lowest level ( $<5$ points); and (2) $\mathrm{PAF}_{+1}$ assuming that the K6 score for every subject would have improved by one level (e.g., a change from $\geq 13$ points to $10-12$ points), except for subjects with the lowest K6 score ( $<5$ points). All PAFs and their $95 \%$ CIs were estimated using the "punafcc package" of Stata/MP 14 (StataCorp., College Station, TX, USA) [35]. Adjustment items for the PAFs were the same as those in Cox Model 2 mentioned above.

All data were analyzed using SAS version 9.4 (SAS Inc., Cary, NC, USA) except for the PAFs and the multiple imputation method. All statistical tests described here were two-sided, and differences at $p<0.05$ were accepted as significant.

\section{Results}

\subsection{Characteristics of the Subjects}

The mean age (SD) of subjects at the baseline was 73.6 (5.9) years, and $46.2 \%$ of them were men. The proportions of the various K6 score groups were $65.2 \%$ for $<5,23.6 \%$ for $5-9,6.5 \%$ for $10-12$, and $4.8 \%$ for $\geq 13$.

Table 1 shows the baseline characteristics of participants according to the K6 score groups. Participants with higher $\mathrm{K} 6$ scores were more likely to have a history of disease, and were less likely to be men, to have better motor function, and to have no lack of social support.

Table 1. Baseline characteristics according to K6 score $(n=12,365)$.

\begin{tabular}{|c|c|c|c|c|}
\hline & \multicolumn{4}{|c|}{ Psychological Distress Scale (K6 Score) } \\
\hline & $<5$ & $5-9$ & $10-12$ & $\geq 13$ \\
\hline$n$ & 8064 & 2912 & 797 & 592 \\
\hline Age, mean (SD) & $\begin{array}{l}73.4 \\
(5.9)\end{array}$ & $\begin{array}{l}73.7 \\
(5.9)\end{array}$ & $\begin{array}{l}74.3 \\
(6.2)\end{array}$ & $\begin{array}{l}74.4 \\
(6.1)\end{array}$ \\
\hline Men, \% & 48.3 & 43.9 & 41.4 & 35.1 \\
\hline \multicolumn{5}{|l|}{ History of disease, $\%$} \\
\hline Stroke & 2.2 & 3.3 & 3.8 & 4.9 \\
\hline Hypertension & 41.9 & 45.9 & 45.4 & 49.7 \\
\hline Myocardial infarction & 4.1 & 6.3 & 7.2 & 7.4 \\
\hline Diabetes mellitus & 11.0 & 13.4 & 13.3 & 15.2 \\
\hline Arthritis & 13.4 & 19.4 & 22.1 & 23.8 \\
\hline Cancer & 8.5 & 8.7 & 11.7 & 12.5 \\
\hline Better motor function, $\%{ }^{1}$ & 84.5 & 73.4 & 64.5 & 53.7 \\
\hline \multicolumn{5}{|l|}{ Smoking, \% } \\
\hline Current & 13.6 & 13.2 & 13.3 & 13.0 \\
\hline Past & 28.1 & 25.9 & 28.7 & 24.6 \\
\hline Never & 58.3 & 60.9 & 58.0 & 62.5 \\
\hline \multicolumn{5}{|l|}{ Alcohol drinking, $\%$} \\
\hline Current & 40.5 & 36.9 & 33.5 & 26.5 \\
\hline Past & 10.4 & 11.5 & 14.5 & 15.6 \\
\hline Never & 49.2 & 51.6 & 52.0 & 57.9 \\
\hline \multicolumn{5}{|l|}{ Body mass index $\left(\mathrm{kg} / \mathrm{m}^{2}\right), \%$} \\
\hline$<18.5$ & 4.1 & 5.8 & 7.3 & 9.2 \\
\hline $18.5-24.9$ & 65.5 & 62.8 & 66.4 & 61.6 \\
\hline$\geq 25$ & 30.5 & 31.4 & 26.4 & 29.2 \\
\hline No lack of social support, $\%$ & 80.4 & 71.8 & 66.9 & 55.4 \\
\hline
\end{tabular}




\subsection{Psychological Distress and Incident Functional Disability}

Table 2 shows the main results for the relationship between the $\mathrm{K} 6$ score and incident functional disability. Significantly higher risk was observed in the higher K6 score groups; the multiple-adjusted HRs (95\% CIs) for incident functional disability were 1.14 (1.06-1.22) for $5-9$ points, 1.28 (1.15-1.43) for $10-12$ points, and $1.62(1.44-1.84)$ for $\geq 13$ points, in comparison with $<5$ points $(p$-trend $<0.001)$.

Table 2. Association between K6 score and incident functional disability $(n=12,365)$.

\begin{tabular}{lccccc}
\hline & \multicolumn{4}{c}{ Psychological Distress Scale (K6 Score) } & \multirow{2}{*}{-Trend } \\
\cline { 2 - 5 } & $<5$ & $\mathbf{5 - 9}$ & $\mathbf{1 0 - 1 2}$ & $\geq \mathbf{1 3}$ & \\
\hline Person-years & $\mathbf{6 3 , 7 2 2}$ & 21,783 & 5498 & 3634 & \\
Event, $n$ & 2720 & 1148 & 362 & 303 & \\
Model 1 $^{1}$ & 1.00 (Reference) & $1.26(1.18-1.35)$ & $1.55(1.39-1.73)$ & $2.01(1.78-2.26)$ & $<0.001$ \\
Model 2 $^{2}$ & 1.00 (Reference) & $1.14(1.06-1.22)$ & $1.28(1.15-1.43)$ & $1.62(1.44-1.84)$ & $<0.001$ \\
\hline
\end{tabular}

${ }^{1}$ Model 1 was adjusted for age and sex. ${ }^{2}$ Model 2 was adjusted for age, sex, history of disease, motor function, smoking, alcohol drinking, body mass index, and social support.

This inverse association did not differ significantly between the sexes $(p$-interaction $=0.651$; Table 3).

Table 3. Association between K6 score and incident functional disability stratified by sex.

\begin{tabular}{|c|c|c|c|c|c|}
\hline & \multicolumn{4}{|c|}{ Psychological Distress Scale (K6 Score) } & \multirow{2}{*}{$p$-Trend } \\
\hline & $<5$ & $5-9$ & $10-12$ & $\geq 13$ & \\
\hline \multicolumn{6}{|c|}{ Men $(n=5709)$} \\
\hline Person-years & 30,300 & 9594 & 2140 & 1250 & \\
\hline Event, $n$ & 1208 & 445 & 142 & 90 & \\
\hline Model $1^{1}$ & 1.00 (Reference) & $1.23(1.10-1.37)$ & $1.74(1.46-2.07)$ & $1.83(1.48-2.27)$ & $<0.001$ \\
\hline Model $2^{2}$ & 1.00 (Reference) & $1.11(0.99-1.24)$ & $1.43(1.20-1.71)$ & $1.32(1.05-1.65)$ & $<0.001$ \\
\hline \multicolumn{6}{|c|}{ Women $(n=6656)$} \\
\hline Person-years & 33,422 & 12,189 & 3358 & 2384 & \\
\hline Event, $n$ & 1512 & 703 & 220 & 213 & \\
\hline Model $1^{1}$ & 1.00 (Reference) & $1.28(1.17-1.40)$ & $1.45(1.26-1.67)$ & $2.09(1.81-2.41)$ & $<0.001$ \\
\hline Model $2^{2}$ & 1.00 (Reference) & $1.16(1.06-1.27)$ & $1.20(1.04-1.39)$ & $1.78(1.53-2.06)$ & $<0.001$ \\
\hline
\end{tabular}

We also obtained similar results even when the multiple imputation method was applied; the multiple-adjusted HRs (95\% CIs) for incident functional disability were 1.14 (1.06-1.22) for 5-9 points, $1.23(1.08-1.39)$ for $10-12$ points, and 1.51 (1.34-1.70) for $\geq 13$ points, in comparison with $<5$ points ( $p$-trend $<0.001$; table not shown).

\subsection{Population Attributable Fraction}

The PAFALL (PAF of K6 score $\geq 5$ ) was 7.2\% (95\% CIs: 4.9-9.4\%). The PAFs for each of the K6 score groups were $3.0 \%$ (95\% CIs: $1.3-4.7 \%$ ) for $5-9$ points, $1.7 \%$ (95\% CIs: $0.9-2.6 \%$ ) for $10-12$ points, and $2.6 \%$ (95\% CIs: $1.8-3.3 \%)$ for $\geq 13$ points.

The $\mathrm{PAF}_{+1}$ was $5.4 \%(95 \%$ CIs: $3.9-6.8 \%)$.

\subsection{Sensitivity Analysis}

We also conducted stratified analysis by age subgroup (Table 4). A dose-response relationship was observed irrespective of the age subgroup $(p$-interaction $=0.425)$. 
Table 4. Sensitivity analysis: stratified by age subgroup.

\begin{tabular}{|c|c|c|c|c|c|}
\hline & \multicolumn{4}{|c|}{ Psychological Distress Scale (K6 Score) } & \multirow{2}{*}{$p$-Trend } \\
\hline & $<5$ & $5-9$ & 10-12 & $\geq 13$ & \\
\hline \multicolumn{6}{|c|}{$<75$ years old $(n=7410)$} \\
\hline Person-years & 42,949 & 14,812 & 3725 & 2429 & \\
\hline Event, $n$ & 974 & 418 & 149 & 117 & \\
\hline Model $1^{1}$ & 1.00 (Reference) & $1.23(1.09-1.37)$ & $1.72(1.45-2.05)$ & $2.16(1.79-2.62)$ & $<0.001$ \\
\hline Model $2^{2}$ & 1.00 (Reference) & $1.10(0.97-1.23)$ & $1.39(1.17-1.66)$ & $1.55(1.27-1.89)$ & $<0.001$ \\
\hline \multicolumn{6}{|c|}{$\geq 75$ years old $(n=4955)$} \\
\hline Person-years & 20,772 & 6971 & 1773 & 1205 & \\
\hline Event, $n$ & 1746 & 730 & 213 & 186 & \\
\hline Model $1^{1}$ & 1.00 (Reference) & $1.28(1.17-1.39)$ & $1.45(1.25-1.67)$ & $1.92(1.65-2.23)$ & $<0.001$ \\
\hline Model $2^{2}$ & 1.00 (Reference) & $1.16(1.07-1.27)$ & $1.21(1.04-1.40)$ & $1.64(1.40-1.91)$ & $<0.001$ \\
\hline
\end{tabular}

${ }^{1}$ Model 1 was adjusted for age (65-69 or 70-74 year in " $<75$ years old"; "75-79, 80-84, or $\geq 85$ years" in " $\geq 75$ years old") and sex. ${ }^{2}$ Model 2 was adjusted for age, sex, history of disease, motor function, smoking, alcohol drinking, body mass index, and social support.

To confirm whether there was a relationship between the K6 score and incident functional disability, irrespective of motor function, we also conducted stratified analysis (Table 5). A dose-response relationship was observed irrespective of motor function $(p$-interaction $=0.425)$.

Table 5. Sensitivity analysis: stratified by motor function subgroup.

\begin{tabular}{|c|c|c|c|c|c|}
\hline & \multicolumn{4}{|c|}{ Psychological Distress Scale (K6 Score) } & \multirow{2}{*}{$p$-Trend } \\
\hline & $<5$ & $5-9$ & $10-12$ & $\geq 13$ & \\
\hline \multicolumn{6}{|l|}{ Lower motor function $(n=2457)$} \\
\hline Person-years & 7444 & 4452 & 1517 & 1266 & \\
\hline Event, $n$ & 692 & 428 & 153 & 167 & \\
\hline Model $1^{1}$ & 1.00 (Reference) & $1.10(0.97-1.24)$ & $1.18(0.99-1.41)$ & $1.69(1.42-2.00)$ & $<0.001$ \\
\hline Model $2^{2}$ & 1.00 (Reference) & $1.09(0.97-1.23)$ & $1.12(0.94-1.34)$ & $1.60(1.34-1.91)$ & $<0.001$ \\
\hline \multicolumn{6}{|l|}{ Better motor function $(n=9354)$} \\
\hline Person-years & 53,773 & 16,375 & 3638 & 2143 & \\
\hline Event, $n$ & 837 & 1887 & 647 & 184 & \\
\hline Model $1^{1}$ & 1.00 (Reference) & $1.20(1.10-1.32)$ & $1.62(1.39-1.88)$ & $1.62(1.34-1.95)$ & $<0.001$ \\
\hline Model $2^{2}$ & 1.00 (Reference) & $1.15(1.05-1.26)$ & $1.48(1.27-1.72)$ & $1.49(1.23-1.80)$ & $<0.001$ \\
\hline
\end{tabular}

${ }^{1}$ Model 1 was adjusted for age (65-69, 70-74, 75-79, 80-84, or $\geq 85$ years) and sex. ${ }^{2}$ Model 2 was adjusted for age, sex, history of disease, smoking, alcohol drinking, body mass index, and social support.

Additionally, we also conducted stratified analysis by social support subgroup (Table 6), and observed a dose-response relationship irrespective of the subgroup $(p$-interaction $=0.986)$.

Table 6. Sensitivity analysis: stratified by social support subgroup.

\begin{tabular}{|c|c|c|c|c|c|}
\hline & \multicolumn{4}{|c|}{ Psychological Distress Scale (K6 Score) } & \multirow{2}{*}{$p$-Trend } \\
\hline & $<5$ & $5-9$ & 10-12 & $\geq 13$ & \\
\hline \multicolumn{6}{|c|}{ No lack $(n=9326)$} \\
\hline Person-years & 50,967 & 15,281 & 3594 & 1875 & \\
\hline Event, $\mathrm{n}$ & 2132 & 840 & 238 & 165 & \\
\hline Model $1^{1}$ & 1.00 (Reference) & $1.34(1.23-1.45)$ & $1.47(1.28-1.68)$ & $1.99(1.70-2.33)$ & $<0.001$ \\
\hline Model $2^{2}$ & 1.00 (Reference) & $1.22(1.13-1.32)$ & $1.21(1.05-1.38)$ & $1.67(1.42-1.96)$ & $<0.001$ \\
\hline \multicolumn{6}{|c|}{ Any lack $(n=2893)$} \\
\hline Person-years & 12,163 & 6179 & 1814 & 1678 & \\
\hline Event, $\mathrm{n}$ & 545 & 296 & 120 & 131 & \\
\hline Model 11 & 1.00 (Reference) & $1.06(0.92-1.22)$ & $1.71(1.40-2.09)$ & $1.88(1.55-2.27)$ & $<0.001$ \\
\hline Model $2^{2}$ & 1.00 (Reference) & $0.97(0.84-1.12)$ & $1.46(1.20-1.79)$ & $1.58(1.30-1.93)$ & $<0.001$ \\
\hline
\end{tabular}

${ }^{1}$ Model 1 was adjusted for age (65-69, 70-74, 75-79, 80-84, or $\geq 85$ years) and sex. ${ }^{2}$ Model 2 was adjusted for age, sex, history of disease, motor function, smoking, alcohol drinking, and body mass index. 


\section{Discussion}

In this cohort study, we observed a significant dose-response relationship between the score on a psychological distress scale (K6) and incident functional disability, and a significantly higher risk even for a mild level of psychological distress (K6 score $\geq 5$ ). The lower risk of incident functional disability was consistent even after stratifying for motor function at the baseline.

The previous study of elderly disaster survivors also observed a significant dose-response relationship between the $\mathrm{K} 6$ (three categories; $\mathrm{K} 6$ score $\leq 9,10-12, \geq 13$ ) and incident functional disability [10]. This previous study focused on a relatively higher level of psychological stress (K6 score $\geq 10$ ), and did not examine mild levels of psychological distress (K6 score $\geq 5$ ).

In the present study, any level of psychological distress (K6 score $\geq 5)$ had considerable impact on incident functional disability $\left(\mathrm{PAF}_{\mathrm{ALL}}=7.2 \%\right)$. However, the degree of impact was smaller than that in a previous cross-sectional study (39.3\%) [12]. Because functional decline is known to be a risk factor for psychological distress, the previous result may have included such a reverse causality effect (i.e., this result of a cross-sectional study might indicate a reciprocal relationship between psychological distress and functional disability) [5]. Therefore, it may not be appropriate to simply compare values of PAF between the present study and the previous cross-sectional study.

Interestingly, the PAF for mild psychological distress (K6 score 5-9: 3.0\%) was higher than that for severe psychological distress (K6 score $\geq 13: 2.6 \%$ ). When psychological distress was summed as mild to moderate (K6 score 5-12: 4.7\%), the PAF was approximately twice that for severe psychological distress (K6 score $\geq 13: 2.6 \%$ ). This finding suggests that mild to moderate psychological distress should also be considered in any public health strategy for comprehensive prevention of functional disability.

Although the HR for severe psychological distress was highest among all the psychological distress levels, the prevalence of severe psychological distress was only one-fifth that of mild psychological distress. This relative difference in prevalence has also been observed in Japanese national statistics and world statistics $[13,36]$. Therefore, the impact of mild to moderate psychological distress would not have been unique to the present study population. Indeed, a previous study of adults (aged 18-64 years) also found that mild psychological distress had a considerable impact (in terms of PAF), and indicated that "mild psychological distress may be associated with more long-term disability than previously known" [11].

Our study had several strengths: (1) it was a large cohort study involving 12,365 persons; and (2) it had a follow-up rate of almost $100 \%(98.6 \%)$.

On the other hand, it also had some limitations. First, psychological distress was measured only once; we did not consider any changes in the participants' psychological status. Second, we did not consider the causes of incident functional disability. Third, the target population was limited to residents in a rural Japanese community. Additional studies conducted in other settings will be needed to confirm the external validity of our findings. Fourth, not all potential confounding factors were considered. For example, we did not consider sensory function, living arrangement, or income.

\section{Conclusions}

Psychological distress, as measured by the K6, was associated with a significantly high risk of incident functional disability in Japanese elderly. Even a mild to moderate level of psychological distress had a considerable impact on incident functional disability.

Author Contributions: T.W. and I.T. designed the research; Y.T. and I.T. collected the data; Y.T. and S.Z. analyzed the data; Y.T., T.W., F.T., and S.Z. wrote the manuscript; and Y.S. and I.T. conducted critical revisions of the manuscript. All authors read and approved the final manuscript.

Funding: This study was supported by a Grant-in-Aid for Scientific Research (B; 17H04130) from Japan Society for the Promotion of Science and Grant-in-Aid for Young Scientists (B; 17K15844) from Japan Society for the Promotion of Science.

Acknowledgments: We would like to thank Yoshiko Nakata and Mami Takahashi for their technical assistance. 
Conflicts of Interest: The authors declare no conflict of interest. None of the funding organizations or sponsors were involved in the study design; in collection, analysis, or interpretation of data; in writing the report; and in making decision to submit the article for publication.

\section{References}

1. Francesca, C.; Ana, L.N.; Jérôme, M.; Frits, T. Help Wanted? Providing and Paying for Long-Term Care; OECD Publishing: Paris, France, 2011.

2. Stuck, A.E.; Walthert, J.M.; Nikolaus, T.; Bula, C.J.; Hohmann, C.; Beck, J.C. Risk factors for functional status decline in community-living elderly people: A systematic literature review. Soc. Sci. Med. 1999, 48, 445-469. [CrossRef]

3. Tas, U.; Verhagen, A.P.; Bierma-Zeinstra, S.M.; Odding, E.; Koes, B.W. Prognostic factors of disability in older people: A systematic review. Br. J. Gen. Pract. 2007, 57, 319-323. [PubMed]

4. Vaughan, L.; Corbin, A.L.; Goveas, J.S. Depression and frailty in later life: A systematic review. Clin. Interv. Aging 2015, 10, 1947-1958. [CrossRef] [PubMed]

5. Soysal, P.; Veronese, N.; Thompson, T.; Kahl, K.G.; Fernandes, B.S.; Prina, A.M.; Solmi, M.; Schofield, P.; Koyanagi, A.; Tseng, P.T.; et al. Relationship between depression and frailty in older adults: A systematic review and meta-analysis. Ageing Res. Rev. 2017, 36, 78-87. [CrossRef] [PubMed]

6. Beekman, A.T.; Copeland, J.R.; Prince, M.J. Review of community prevalence of depression in later life. Br. J. Psychiatry 1999, 174, 307-311. [CrossRef] [PubMed]

7. Lawrence, P.; Fulbrook, P. Protocol for a pragmatic randomised controlled trial to evaluate effects of a brief intervention for emergency department attendees who present with moderate or high levels of non-specific psychological distress: A pilot study. Pilot Feasibility Stud. 2015, 1, 33. [CrossRef] [PubMed]

8. Russ, T.C.; Stamatakis, E.; Hamer, M.; Starr, J.M.; Kivimaki, M.; Batty, G.D. Association between psychological distress and mortality: Individual participant pooled analysis of 10 prospective cohort studies. BMJ 2012, 345, e4933. [CrossRef] [PubMed]

9. Lazzarino, A.I.; Hamer, M.; Stamatakis, E.; Steptoe, A. The combined association of psychological distress and socioeconomic status with all-cause mortality: A national cohort study. JAMA Intern. Med. 2013, 173, 22-27. [CrossRef] [PubMed]

10. Tanji, F.; Sugawara, Y.; Tomata, Y.; Watanabe, T.; Sugiyama, K.; Kaiho, Y.; Tomita, H.; Tsuji, I. Psychological distress and the incident risk of functional disability in elderly survivors after the Great East Japan Earthquake. J. Affect. Disord. 2017, 221, 145-150. [CrossRef] [PubMed]

11. Rai, D.; Kosidou, K.; Lundberg, M.; Araya, R.; Lewis, G.; Magnusson, C. Psychological distress and risk of long-term disability: Population-based longitudinal study. J. Epidemiol. Community Health 2012, 66, 586-592. [CrossRef] [PubMed]

12. Monma, T.; Takeda, F.; Noguchi, H.; Tamiya, N. Age and sex differences of risk factors of activity limitations in Japanese older adults. Geriatr. Gerontol. Int. 2016, 16, 670-678. [CrossRef] [PubMed]

13. Ministry of Health, Labour and Welfare. Comprehensive Survey of Living Conditions in 2016. Available online: https://www.mhlw.go.jp/english/database/db-hss/cslc-tables.html (accessed on 8 November 2018).

14. Chou, W.T.; Tomata, Y.; Watanabe, T.; Sugawara, Y.; Kakizaki, M.; Tsuji, I. Relationships between changes in time spent walking since middle age and incident functional disability. Prev. Med. 2014, 59, 68-72. [CrossRef] [PubMed]

15. Kessler, R.C.; Andrews, G.; Colpe, L.J.; Hiripi, E.; Mroczek, D.K.; Normand, S.L.; Walters, E.E.; Zaslavsky, A.M. Short screening scales to monitor population prevalences and trends in non-specific psychological distress. Psychol. Med. 2002, 32, 959-976. [CrossRef] [PubMed]

16. Furukawa, T.A.; Kawakami, N.; Saitoh, M.; Ono, Y.; Nakane, Y.; Nakamura, Y.; Tachimori, H.; Iwata, N.; Uda, H.; Nakane, H.; et al. The performance of the Japanese version of the K6 and K10 in the World Mental Health Survey Japan. Int. J. Methods Psychiatr. Res. 2008, 17, 152-158. [CrossRef] [PubMed]

17. Sakurai, K.; Nishi, A.; Kondo, K.; Yanagida, K.; Kawakami, N. Screening performance of K6/K10 and other screening instruments for mood and anxiety disorders in Japan. Psychiatry Clin. Neurosci. 2011, 65, 434-441. [CrossRef] [PubMed] 
18. Tanji, F.; Tomata, Y.; Sekiguchi, T.; Tsuji, I. Period of residence in prefabricated temporary housing and psychological distress after the Great East Japan Earthquake: A longitudinal study. BMJ Open 2018, 8, e018211. [CrossRef] [PubMed]

19. Fushimi, M.; Saito, S.; Shimizu, T.; Kudo, Y.; Seki, M.; Murata, K. Prevalence of psychological distress, as measured by the Kessler 6 (K6), and related factors in Japanese employees. Community Ment. Health J. 2012, 48, 328-335. [CrossRef] [PubMed]

20. Sone, T.; Nakaya, N.; Sugawara, Y.; Tomata, Y.; Watanabe, T.; Tsuji, I. Longitudinal association between time-varying social isolation and psychological distress after the Great East Japan Earthquake. Soc. Sci. Med. 2016, 152, 96-101. [CrossRef] [PubMed]

21. Watanabe, Z.; Iwama, N.; Nishigori, H.; Nishigori, T.; Mizuno, S.; Sakurai, K.; Ishikuro, M.; Obara, T.; Tatsuta, N.; Nishijima, I.; et al. Psychological distress during pregnancy in Miyagi after the Great East Japan Earthquake: The Japan Environment and Children's Study. J. Affect. Disord. 2016, 190, 341-348. [CrossRef] [PubMed]

22. Yokoyama, Y.; Otsuka, K.; Kawakami, N.; Kobayashi, S.; Ogawa, A.; Tannno, K.; Onoda, T.; Yaegashi, Y.; Sakata, K. Mental health and related factors after the Great East Japan earthquake and tsunami. PLoS ONE 2014, 9, e102497. [CrossRef] [PubMed]

23. Tomata, Y.; Hozawa, A.; Ohmori-Matsuda, K.; Nagai, M.; Sugawara, Y.; Nitta, A.; Kuriyama, S.; Tsuji, I. [Validation of the Kihon Checklist for predicting the risk of 1-year incident long-term care insurance certification: The Ohsaki Cohort 2006 Study]. Nihon Koshu Eisei Zasshi 2011, 58, 3-13. [PubMed]

24. Muraoka, Y.; Ikichi, A.; Ihara, K. The physical and psychological and social background factor of elderly depression in the community. Ronen Seishin Igaku Zasshi 1996, 7, 397-407.

25. Kurimoto, A.; Awata, S.; Ohkubo, T.; Tsubota-Utsugi, M.; Asayama, K.; Takahashi, K.; Suenaga, K.; Satoh, H.; Imai, Y. Reliability and validity of the Japanese version of the abbreviated Lubben Social Network Scale. Nippon Ronen Igakkai Zasshi 2011, 48, 149-157. [CrossRef] [PubMed]

26. Zhang, S.; Tomata, Y.; Newson, R.B.; Sugawara, Y.; Tsuji, I. Combined healthy lifestyle behaviours and incident disability in an elderly population: The Ohsaki Cohort 2006 Study. J. Epidemiol. Community Health 2018. [CrossRef] [PubMed]

27. Tomata, Y.; Kakizaki, M.; Nakaya, N.; Tsuboya, T.; Sone, T.; Kuriyama, S.; Hozawa, A.; Tsuji, I. Green tea consumption and the risk of incident functional disability in elderly Japanese: The Ohsaki Cohort 2006 Study. Am. J. Clin. Nutr. 2012, 95, 732-739. [CrossRef] [PubMed]

28. Mori, K.; Kaiho, Y.; Tomata, Y.; Narita, M.; Tanji, F.; Sugiyama, K.; Sugawara, Y.; Tsuji, I. Sense of life worth living (ikigai) and incident functional disability in elderly Japanese: The Tsurugaya Project. J. Psychosom. Res. 2017, 95, 62-67. [CrossRef] [PubMed]

29. Ikegami, N. Public long-term care insurance in Japan. JAMA 1997, 278, 1310-1314. [CrossRef] [PubMed]

30. Tsutsui, T.; Muramatsu, N. Care-needs certification in the long-term care insurance system of Japan. J. Am. Geriatr. Soc. 2005, 53, 522-527. [CrossRef] [PubMed]

31. Imahashi, K.; Kawagoe, M.; Eto, F.; Haga, N. Clinical status and dependency of the elderly requiring long-term care in Japan. Tohoku J. Exp. Med. 2007, 212, 229-238. [CrossRef] [PubMed]

32. Arai, Y.; Zarit, S.H.; Kumamoto, K.; Takeda, A. Are there inequities in the assessment of dementia under Japan's LTC insurance system? Int. J. Geriatr. Psychiatry 2003, 18, 346-352. [CrossRef] [PubMed]

33. Hozawa, A.; Sugawara, Y.; Tomata, Y.; Kakizaki, M.; Tsuboya, T.; Ohmori-Matsuda, K.; Nakaya, N.; Kuriyama, S.; Fukao, A.; Tsuji, I. Relationship between serum isoflavone levels and disability-free survival among community-dwelling elderly individuals: Nested case-control study of the Tsurugaya project. J. Gerontol. A Biol. Sci. Med. Sci. 2013, 68, 465-472. [CrossRef] [PubMed]

34. Tomata, Y.; Watanabe, T.; Sugiyama, K.; Zhang, S.; Sugawara, Y.; Tsuji, I. Effects of a Community-Based Program for Oral Health and Nutrition on Cost-Effectiveness by Preventing Disability in Japanese Frail Elderly: A Quasi-Experimental Study Using Propensity Score Matching. J. Am. Med. Directors Assoc. 2017, 18, 678-685. [CrossRef] [PubMed] 
35. Newson, R. PUNAFCC: Stata module to compute population attributable fractions for case-control and survival studies. 2017. Available online: http://ideas.repec.org/c/boc/bocode/s457354.html (accessed on 8 November 2018).

36. Lawrence, D.; Mitrou, F.; Zubrick, S.R. Non-specific psychological distress, smoking status and smoking cessation: United States National Health Interview Survey 2005. BMC Public Health 2011, 11, 256. [CrossRef] [PubMed]

(c)

(C) 2018 by the authors. Licensee MDPI, Basel, Switzerland. This article is an open access article distributed under the terms and conditions of the Creative Commons Attribution (CC BY) license (http://creativecommons.org/licenses/by/4.0/). 